\title{
Breastfeeding Knowledge, Altitude and Practices of Lactating Mothers in Mwanakia-A Case of Nairobi Metropolis.
}

\author{
Dr. Nkirigacha-Miriti Evayline Muthoni \\ Lecturer, Department of Foods, Nutrition and Dietetics. \\ School of Health and Human Sciences. Pwani University P.O BOX 195, KILIFI
}

\begin{abstract}
The objective of the study to examine the breastfeeding knowledge, altitude and practices of lactating mothers 0-6 postpartum. This cross sectional study was conducted on 260 lactating women living in Mwanamukia, Nairobi Kenya. A structured questionnaire was used on social, socio-economic characteristics. SPSS version 20 and analyzed using descriptive statistics and Pearson correlation coefficient determined associations. More than half of the respondents were literate, married and lived in male headed households. Others business people, single and Meru ethnicity. Majority 36-40 years age category. Majority $(61.6 \%)$ participated in urban agriculture. $57.3 \%$ of the respondents owned land. $88.5 \%$ had heard about exclusive breastfeeding, 96.2\% breastfed exclusively for 4 months, 57.7 knew infant should be breastfed immediately after birth, $26.5 \%$ breastfeed after2-24 hours of delivery.67.3\% frequent suckling does not increase milk production. 46.9\% agreed an infant first food breastmilk, 26.5\% cow's milk and $23.8 \%$ porridge. $94.2 \%$ altitude exclusively breastfeed 6 months, $46.1 \%$ believed feed infant breast milk while $30.4 \%$ cow's milk, $23.4 \%$ porridge. $48.1 \%$ breast milk sufficient, $82.7 \%$ colostrum be fed to infant, $17.3 \%$ colostrum. $81.2 \%$ felt good giving infant something to eat before 6 months, $18.8 \%$ afraid child well cry.52.7\% felt exclusively breastfed not healthier than exclusively breastfed.94.1\% breastfed last child. $50 \%$ breastfed immediately, $29.2 \%$ gave something after one month, $48.1 \%$ gave something after 2 months.52.3\% breastfed on demand, 34.2\% when child cried. Illiterate Mothers had inappropriate feeding practices(OR1.578, CI 1.762-2.292). The study concludes that knowledge and practice did not have any relationship, altitude influenced feeding habits.
\end{abstract}

Key words: Lactating mothers; breastfeeding; socio-economic characteristics; knowledge; altitude; practices.

\section{Introduction}

Malnutrition is responsible for $60 \%$ of the 10.9 million deaths that occur annually among children. Inappropriate feeding practices, nutrition knowledge and the altitude of the mothers and other care givers is usually associated with these deaths, which occur during the first year of life. The World Health Organization (WHO) recommends timely initiation of breastfeeding within the first hour of delivery. Breastfeeding should be continued through to 24 months together with appropriate complementary feeding (According to the World Health Organization (WHO), breast milk has a complete nutritional requirements that a baby needs for health and development. It is also safe and contains anti-bodies that help protect infants and boosts immunity. It also contributes to reduced infants, and boost immunity. It is the first communication pathway between the mother and her infant. It also contributes to reduced infant morbidity. It also contributes to reduced infant morbidity and mortality due to diarrhea, respiratory or ear infections and other complications. It is the founder mental right of a child to receive exclusive breastfeeding after birth (Sungh et al., 2018, Grage et al., 2015,WHO, 2013).Exclusive breastfeeding is defined as initiating breastfeeding immediately after birth and not giving other solid food (including water), to the infant (GEAG ETAL., 2015, Singn et al.,2018). Breast milk is economical, it's always available, hygienic and comes at the 
right temperature for the baby. Exclusive breast feeding is healthy for development of immunity for proper physiological and psychological development of the infant (Nkirigacha et al., 2016, WHO, 2013). Breast milk also delays the return of fertility and reduces the risk of developing breast and ovarian cancer, (WHO, 2013).

Breast feeding is known to promote optimal nutrition for infants during early post-natal life. One of the most effective strategies for reducing infant morbidity and mortality in resource poor settings ( e.i human and infrastructureal constraits) is the promotion of exclusive breastfeeding for the first six months of the infant's life. According to the Lancet's series on child survival, increasing breastfeeding prevalence of optimal levels could reduce $13 \%$ of all child deaths in low-income countries (Jones et al., 2003, Mogre, et al.,2016). Suboptimal breastfeeding was ranked by the global burden burden of Diseases, Injuries and Risk Factor Study (DIRFS) to be the second largest risk factor for children under five,accounting for the loss of 47.5 million Disability Adjusted Life Years (DALYs) in 2010 (Lim et al., 2013, Mogre et al.,2016). SubSaharan Africa has been the worst affected with the highest proportion of disease burden associated to suboptimal breastfeeding (Lim,et al.,2013, Mogre et al.,2016). The World Health Organization (WHO) recommends timely initiation of breastfeeding within the first hour of birth, then exclusively breastfeed up to six months and continued breastfeeding through to 24 months together with appropriate complementary feeding (Jones et al., 2003, WHO, UNICEF, 2003, Mogre et al., 2016). Introducing complementary feeding early or too late is appropriate and especially using inadequate or unsafe foods. Only a mere $38 \%$ of the infants worldwide are exclusively breastfed during the first six months of life (YCFV, 2011-2015). When an infant is not exclusively breastfed then, this child stands to face life challenges such as frequent bouts of sickness and impaired development (Singh et al., 2018, Nkirigacha et al., 2016). The American Academy of Padiatrics (AAP), states that exclusive breastfeeding should be the reference and normative module against which all alternative health, development and all other short and long-term outcomes must be measured (AAP, 2005). The World Health Organization states that breastfeeding is the normal way of providing young infants with the nutrients they need for healthy growth and development (Tsedekeet et al., 2014). Guiding principles for complementary feeding of the breastfed child on WHO are as follows;

- Practice exclusive breastfeeding from birth to 6 months of age, and introduce complementary foods at 6 months of age (180 days) while continuing to breastfeed.

- Continue frequent, on-demand breastfeeding until 2 years of age or beyond.

- Practice responsive feeding applying the principles of psychosocial care.

- Practice good hygiene and proper handling.

- Start at 6 months of age with small amounts of food and increase the quantity as the child gets older, while maintaining frequent breastfeeding.

- Gradually increase food consistency and variety as the infant grows older, adapting to the infants requirements and abilities.

- Increase the number of times that the child is fed complementary foods as the child gets older.

- Feed a variety of nutrient-rich foods to ensure that all nutrients needs are met.

- Use fortified complementary foods or vitamin supplements for the infant as needed.

- Increase fluid intake during illness, including more frequent, favorite foods. After illness give food more often than usual and encourage the child to eat more (WHO, 2002).

Poor practices and altitudes toward exclusive breast feeding have been reported to be among the major reasons for poor health outcomes among children, particularly in developing countries. The six causes of $90 \%$ of under-five child mortality world-wide are acute respiratory infections, diarrhea, measles and neonates conditions are easily preventable (UN-MDG SUMMIT, 2010). Breastfeeding strengthens child immunity, this guarantees child survival and health and reduces their vulnerability to diseases such as malaria, pneumonia and diarrhea. These diseases are responsible for the death of more than half of the children under five years (Jones et al., 2003).

\section{Method}

\section{Design and methods}

This was a cross sectional study descriptive design targeting lactating mothers. The sampling unit was households. The study was done at mwanamukia area of Nairobi metropolis. The sample size was 260 
respondents who were lactating mothers with children below 6 months. The area of study was selected randomly. With the help of the Assistant chief and headmen the researcher was able to choose villages from which she made a list of households with lactating mothers. The activities going on these households were also noted. Sample size per village was drawn randomly for each village.

Data was collected using a structured and previously pretested questionnaires. Data on the respondents' socio-demographics and socio- economics was obtained. This included age, ethnicity, marital status, education levels, monthly income, family size, occupation, number of children six months old in each household, heads of households, maternal breastfeeding knowledge, altitude and practices.

\section{Data analysis}

\section{Socio-demographic and socioeconomic}

Responses on Socio-demographic and socioeconomic were coded and analyzed quantitatively, using statistical package SPSS.

\section{Maternal knowledge, altitude and practices}

Responses on maternal knowledge on exclusive breastfeeding, were coded and analyzed quantitatively, using statistical package SPSS version 20. Information on maternal altitude towards exclusive breastfeeding for six months was also processed the same way. The exclusive breastfeeding practices for six months from the interviews was organized into categories then into themes for meaningful interpretation.

\section{Statistical analysis}

Upon study completion, questionnaires were summarized. Data was then entered and cleaned using statistical packages for social sciences (SPSS version 20). The data was then analyzed per household. Binary logistic regressions were used to determine the strength of associations between independent and dependent variables using odds ratios and $95 \%$ Confidence Intervals. Finally a multivariate logistic regression analysis was made to identify the predictors of maternal knowledge, altitude and practices about exclusive breastfeeding. Frequencies mean, standard deviations, percentages were determined.

Items for the knowledge, altitude and practice of exclusive breastfeeding scales of the questionnaire were adapted from the Food and Agriculture Organization of the United Nations (FAO) guidelines for assessing nutrition-related knowledge, altitude and practices (KAP) manual. This manual contains guidelines that serve as a reference guide and practical tools for undertaking high quality evaluation of nutrition and health related knowledge, altitude and practices that are at the community level.

\section{Results}

Socio-demographic and socioeconomic characteristics of lactating mothers

Age

The minimum age of the respondents was 20 while the maximum age was 49 . The highest numbers of respondents were aged between $36-40$ years as shown in figure 1 . These results show that majority of the respondents are young people.

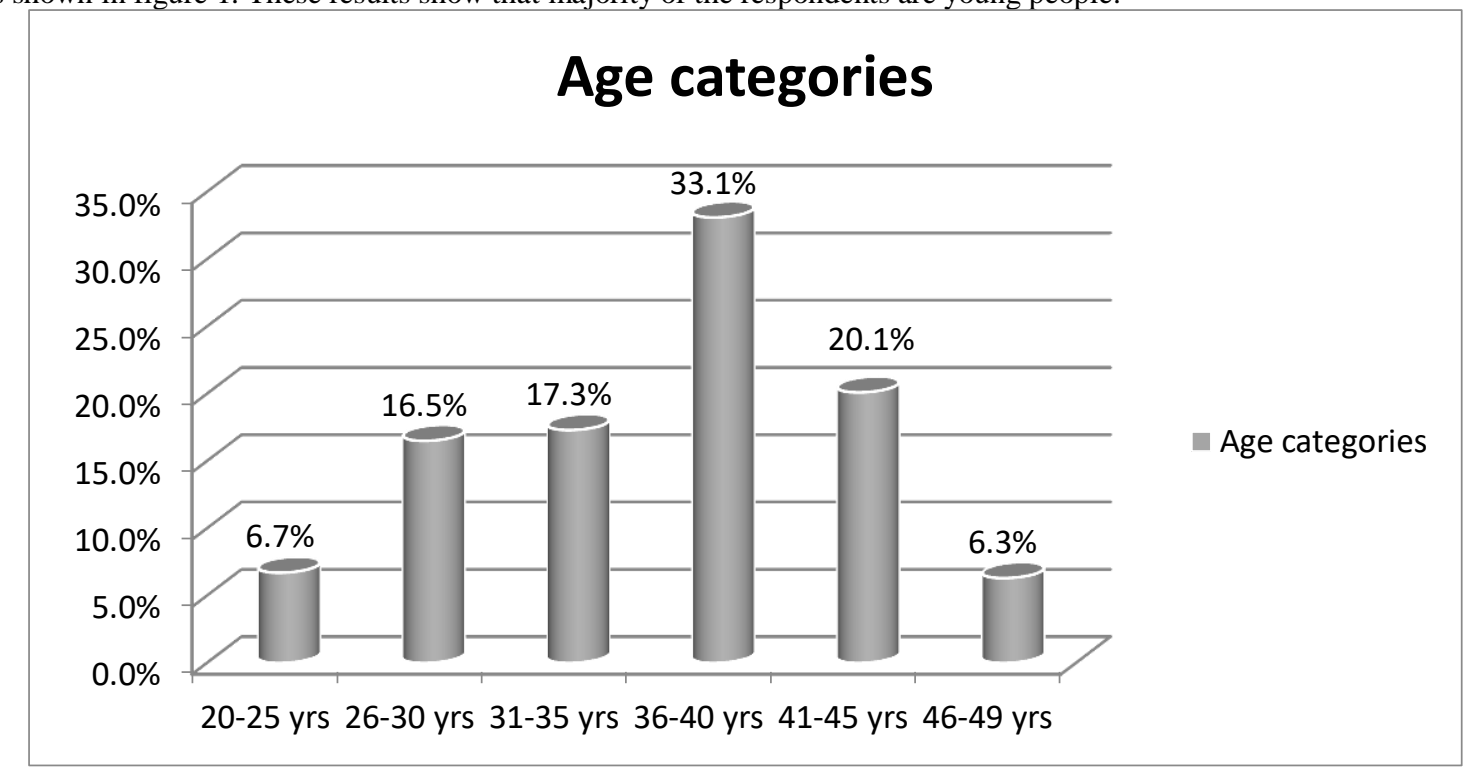

Figure 1: age of respondents in the study area 


\section{Ethnicity}

The study had respondents from different ethnic backgrounds. Meru (25.5 percent), Luhya (17.3 percent) and Kikuyu (16.1 percent) formed the majority of the respondents as shown in figure 1. This shows that the area is a metropolis area with migrants from different regions of the country

\section{Marital status of the mothers}

Majority were married (62.7\%), Single mothers were $25.4 \%$. The remaining mothers were either divorced or widowed and each at less than $10 \%$.

Table 1: Distribution of the mothers by marital status

\begin{tabular}{|c|c|c|}
\hline Marital status & $\begin{array}{l}\text { Number of respondents } \\
\text { N=260 }\end{array}$ & Percentage (\%) \\
\hline Divorced & 16 & 6.2 \\
\hline Widow & 15 & 5.7 \\
\hline Married & 163 & 62.7 \\
\hline Single & 66 & 25.4 \\
\hline
\end{tabular}

\section{Education level of the mothers}

The education levels of the mothers are shown in Table 1. As the Results show that, $44.6 \%$ had primary and $40 \%$ had secondary education. The remaining mothers had either college diploma or university degree. There were no illiterate mothers. That means that all the mothers participating in the study had at least primary level education. This means that they were all capable of accessing nutrition and health information from the common sources available. The main education level attained was primary at $44.6 \%$ which is higher than the average of $43 \%$ indicated by KDHS study (2014).

Table 2: Distribution of mothers by education level

\begin{tabular}{|l|l|l|}
\hline \multicolumn{1}{|c|}{ Education level } & $\begin{array}{l}\text { Number of respondents } \\
(\mathrm{N}=260)\end{array}$ & Percent of mothers \\
\hline Illiterate & 21 & 8.1 \\
\hline Primary level & 116 & 44.6 \\
\hline Secondary (O level) & 90 & 34.6 \\
\hline Secondary (A level) & 14 & 5.4 \\
\hline College & 17 & 6.5 \\
\hline University & 2 & 0.8 \\
\hline
\end{tabular}

\section{The monthly income}

The average monthly income was $27,154.12$ Kenyan shillings. The income category with the highest number was $11,000-20,000$. Findings show that most families survive on less than a dollar per day.

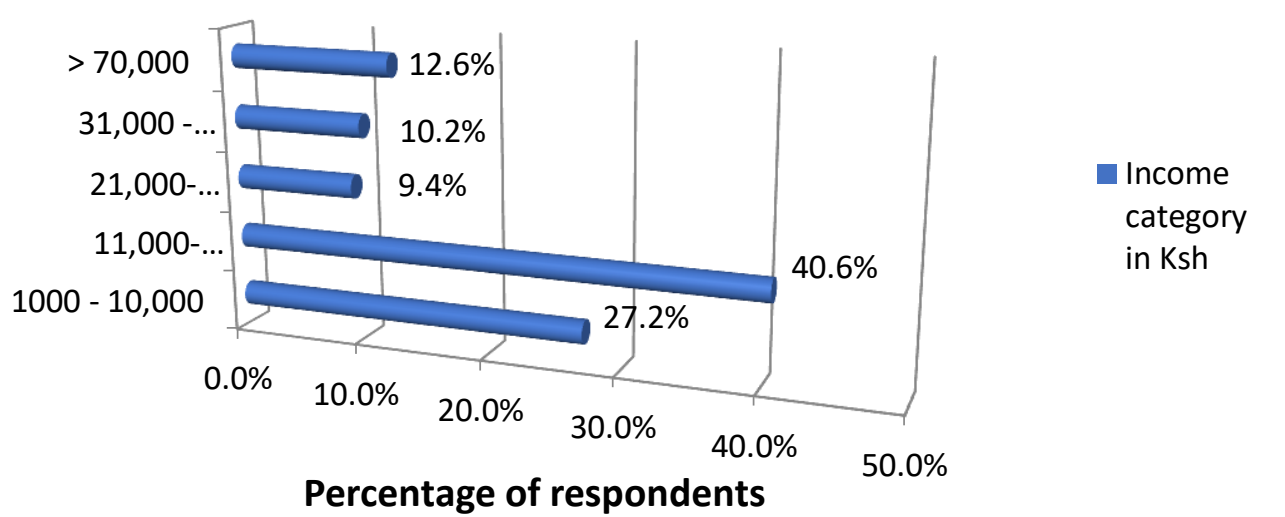

Figure 2: average monthly income of respondents in the study area 
Number of people living in the household

The maximum number of people living in households was 12 . The average number of people was 6 . Household members' between $1-5$ was the highest as shown in figure 4 . This shows that most families are averagely sized.

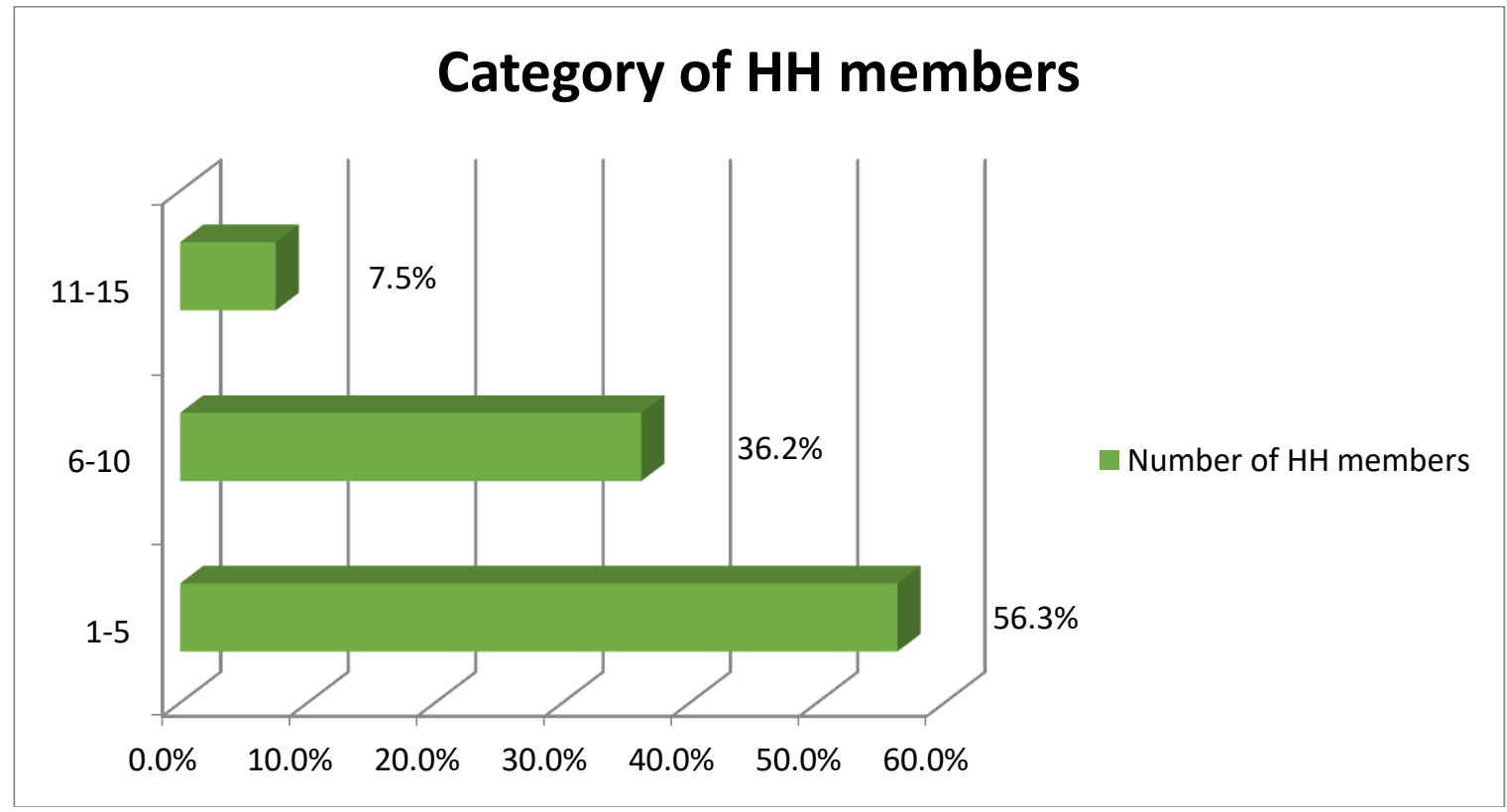

Figure 3: members in households

\section{Occupation}

There were many differing occupations among the respondents. Majority of the respondents were business people (28.6\%) and housewives (23.9\%) as shown in figure 6. This shows that majority of the respondents are in the informal sector.

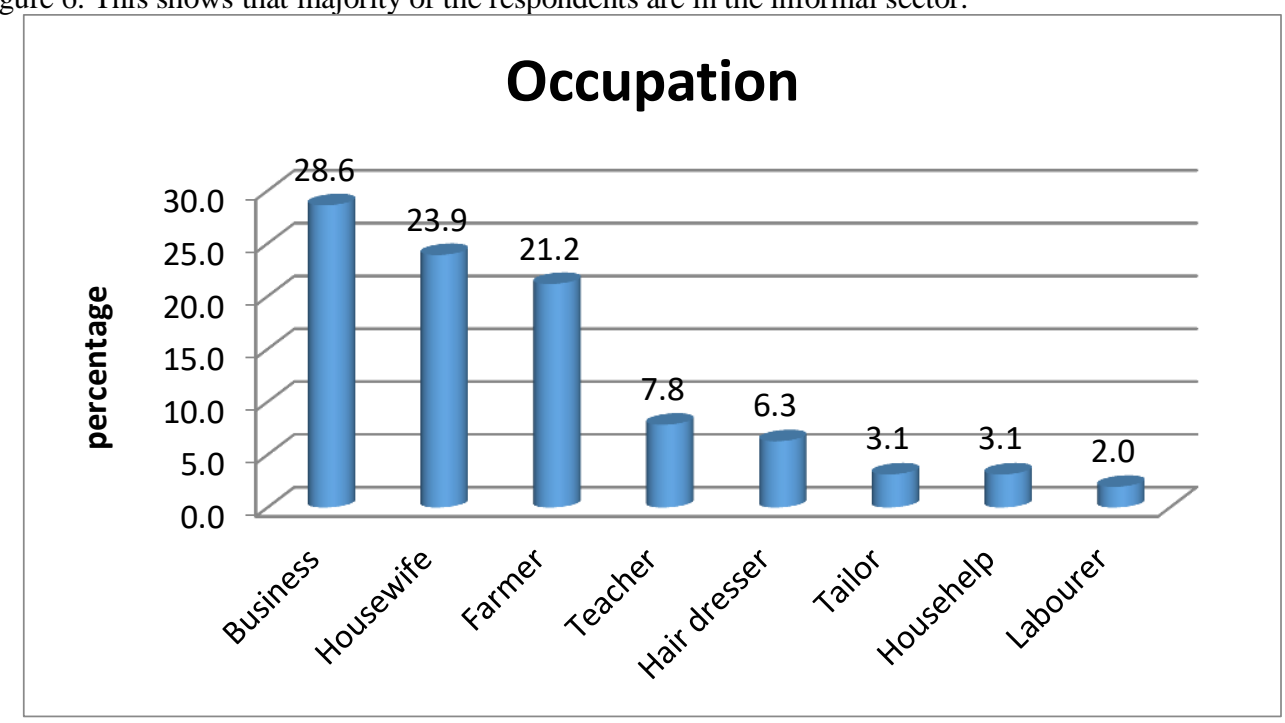

Figure 4: Occupation of respondents in the study area

\section{The number of children in the $\mathbf{H H}$}

The maximum number of children in the household was 10 . The average was 4 children. The category of $0-2$ children per household had the highest percentage (37\%) as shown in figure 7. 


\section{Number of living children}

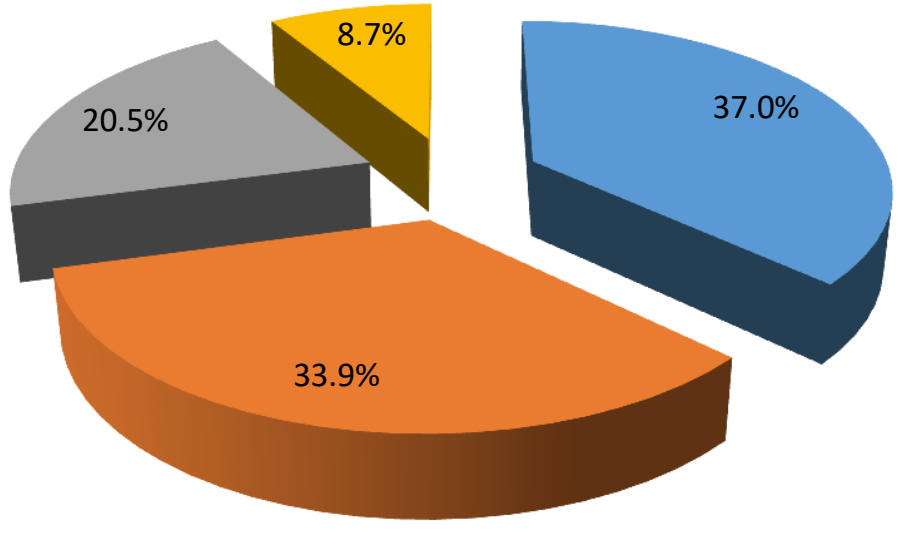

Figure 5: number of children in the respondents' households

\section{Children 5 years and below}

The Maximum number of children under 5 years was 4 in a household. The average was 1 in the respondents' households as shown in figure 8 . This indicates that most respondents practice child spacing.

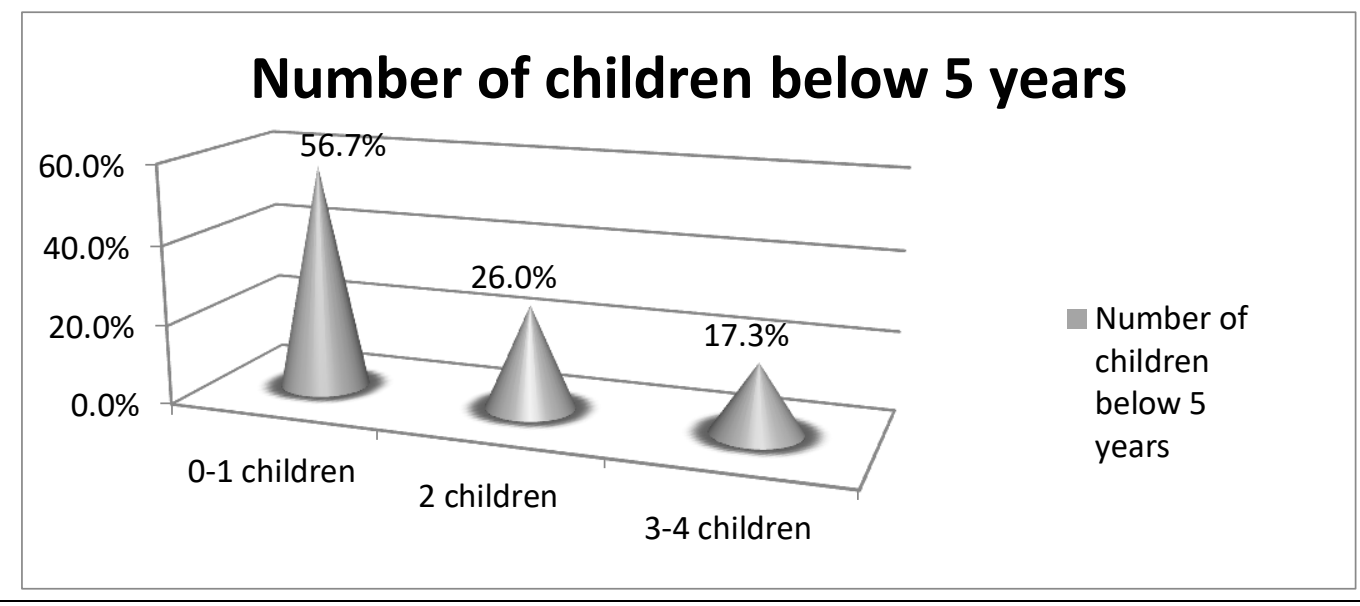

Figure 8: number of children below 5 years in the respondents' households

The head of the household

51.2 percent of respondents household were headed by men while 34.6 percent were headed by women as shown in figure 9 below.

\section{The knowledge of lactating mothers on breast feeding}

The results show that majority $(88.5 \%)$ of lactating mothers had heard about exclusive breast feeding, while $11.5 \%$ said they had no prior knowledge on breast feeding. Majority of the respondents (96.2\%) reported having breastfed their infants exclusively for $<4$ months and 3.8\% breastfed exclusively for $>6$ months. $57.7 \%$ said an infant should be breastfed immediately after birth and 26.65 said it should be breastfed between 2-24 hours after delivery.67.3\% said that frequent suckling does not help in production of breast milk, $96.9 \%$ said exclusive breast feeding should be carried out for about 6 months. $49.6 \%$ said the infant should be fed on the breast milk as the first food and $26.5 \%$ said the baby should be given cow's milk with water while $23.8 \%$ said the infant can be given porridge.

Table 1. Knowledge of respondents on breast feeding in the study area

\begin{tabular}{|l|c|l|l|}
\hline Variables & \multicolumn{1}{|c|}{ Yes } & Frequency & Percentage \\
\hline $\begin{array}{l}\text { Have you ever heard about } \\
\text { exclusive breastfeeding }\end{array}$ & $\bullet \quad$ No & 230 & 88.5 \\
\hline $\begin{array}{l}\text { How long should an infant be } \\
\text { exclusively breastfed }\end{array}$ & $\bullet<4$ months & 250 & 11.5 \\
\hline & $\bullet>6$ months & 10 & 96.2 \\
\hline $\begin{array}{l}\text { When should breastfeeding } \\
\text { be initiated after delivery? }\end{array}$ & $\bullet$ Immediately & 150 & 3.8 \\
& $\bullet$ 2-24hours & 69 & 57.7 \\
& & 41 & 26.5 \\
\hline
\end{tabular}




\begin{tabular}{|l|l|l|l|}
\hline $\begin{array}{l}\text { Does frequent suckling help } \\
\text { in milk production? }\end{array}$ & $\bullet$ Yes & 85 & 32.7 \\
& $\bullet$ No & 67.3 \\
\hline $\begin{array}{l}\text { For how long should } \\
\text { exclusive breastfeeding be } \\
\text { done? }\end{array}$ & $\bullet$ About 6 months & 252 & 0.8 \\
& $\bullet$ Beyond 6 months & 6 & 96.9 \\
\hline $\begin{array}{l}\text { Which of the following do } \\
\text { you think is important for } \\
\text { new born? }\end{array}$ & $\bullet$ Breast milk only & 129 & 0.2 \\
\hline
\end{tabular}

\section{The altitude of the respondents towards breastfeeding}

Majority (94.2\%) of the respondents felt that exclusive breast feeding for the past 6 months was beneficial. $46.1 \%$ preferred to feed their infants with breast milk, 30.4\% preferred cow's milk and 23.4\% preferred breast milk and porridge as the first food for the first 6 months. Lactating mothers $(48.1 \%)$ felt that exclusive breast feeding is useful and sufficient but majority felt that the infant can grow well with breast milk and other feeds. $82.7 \%$ believed that the first milk should not be discarded and $17.3 \%$ believed that it should be discarded. $81.2 \%$ felt good when they gave their infant something to eat other than breast milk and $18.8 \%$ felt afraid that the child may cry thereafter. $52.7 \%$ agreed that children who are exclusively breastfed were not healthier than those exclusively breast fed and $47.3 \%$ said that exclusively breast fed children were more healthier.

Table 2. The altitude of lactating mothers on breastfeeding.

\begin{tabular}{|c|c|c|c|}
\hline Variables & & Frequency & Percentage \\
\hline $\begin{array}{l}\text { Do you feel that exclusive } \\
\text { breastfeeding for the first } 6 \\
\text { months is beneficial? }\end{array}$ & $\begin{array}{ll}- & \text { Yes } \\
\text { - } & \text { No } \\
\end{array}$ & $\begin{array}{l}245 \\
15\end{array}$ & $\begin{array}{l}94.2 \\
5.8\end{array}$ \\
\hline $\begin{array}{l}\text { What do you prefer to feed } \\
\text { your baby with for the first } 6 \\
\text { months? }\end{array}$ & $\begin{array}{ll}\text { - } & \text { Breast milk } \\
\text { - } & \text { Cow's milk } \\
\text { - } & \text { Breast milk and } \\
& \text { porridge } \\
\end{array}$ & $\begin{array}{l}120 \\
79 \\
61\end{array}$ & $\begin{array}{l}46.1 \\
30.4 \\
23.4\end{array}$ \\
\hline $\begin{array}{l}\text { What is your opinion about } \\
\text { exclusive breast feeding in } \\
\text { the first } 6 \text { months }\end{array}$ & $\begin{array}{l}\text { - It is sufficient and } \\
\text { useful } \\
\text { The child can still } \\
\text { grow well } \\
\text { combining breast } \\
\text { milk and porridge }\end{array}$ & $\begin{array}{l}125 \\
135\end{array}$ & $\begin{array}{l}48.1 \\
51.9\end{array}$ \\
\hline $\begin{array}{l}\text { Do you believe that the first } \\
\text { milk (colostrum) should be } \\
\text { discarded? }\end{array}$ & $\begin{array}{ll}\text { - } & \text { Yes } \\
\text { - } & \text { No }\end{array}$ & $\begin{array}{l}215 \\
45\end{array}$ & $\begin{array}{l}17.3 \\
82.7\end{array}$ \\
\hline $\begin{array}{l}\text { How did you feel when you } \\
\text { gave your baby extra food } \\
\text { other than breast milk }\end{array}$ & $\begin{array}{ll} & \text { Good } \\
\text { - Afraid the child } \\
\text { may cry }\end{array}$ & $\begin{array}{l}211 \\
49\end{array}$ & $\begin{array}{l}81.2 \\
18.8\end{array}$ \\
\hline $\begin{array}{l}\text { Do you agree that an } \\
\text { exclusively breast fed child is } \\
\text { healthier than child who takes } \\
\text { additional food? }\end{array}$ & $\begin{array}{ll}\text { - } & \text { Yes } \\
\text { - } & \text { No } \\
\text { - } & \text { Not sure }\end{array}$ & $\begin{array}{l}98 \\
137 \\
25\end{array}$ & $\begin{array}{l}47.3 \\
52.7 \\
9.6\end{array}$ \\
\hline
\end{tabular}

\section{Practices of breastfeeding by lactating mothers}

Majority $94.1 \%$ of the lactating mothers breastfed their last child, 50\% started breastfeeding immediately after delivery and $48.1 \%$ give their child other items to eat than breast milk after 2 months, and $29.2 \%$ give anything other than breast milk after one month. $52.3 \%$ breast fed on demand and $34.2 \%$ breastfed when the child cried. 86.5\% gave their infant something else other than breast milk before six months.

Table 3. Breast feeding practices of the lactating mothers

\begin{tabular}{|l|l|l|l|}
\hline Variables & Frequency & Percentage \\
\hline $\begin{array}{l}\text { Did you breastfeed your last } \\
\text { child? }\end{array}$ & Yes & 245 & 94.2 \\
& No & 15 & 5.8 \\
\hline $\begin{array}{l}\text { When did you start } \\
\text { breastfeeding your last child? }\end{array}$ & $\begin{array}{l}\text { Immediately } \\
\text { After 1 hour } \\
\text { After 24 hours }\end{array}$ & 130 & 50 \\
\hline $\begin{array}{l}\text { Did you give the last child } \\
\text { anything other than breast } \\
\text { milk after delivery }\end{array}$ & No & 51 & 30.4 \\
\hline $\begin{array}{l}\text { After how long did you give } \\
\text { your child anything other }\end{array}$ & After 1 month & 140 & 19.6 \\
\hline
\end{tabular}




\begin{tabular}{|l|l|l|l|}
\hline than breast milk & After 6 months & 59 & 22.7 \\
\hline How frequently did you & On demand & 136 & 52.3 \\
breastfeed your last child? & After crying & 89 & 34.2 \\
& Randomly & 35 & 13.5 \\
\hline Did you give your child & Yes & 141 & 86.5 \\
anything else before 6 months & No & 119 & 13.5 \\
\hline
\end{tabular}

Table. 4: Association of characteristics with the breast feeding practices of lactating mothers.

\begin{tabular}{|l|l|l|l|l|l|}
\hline Variable & & Frequency & percent & OR(95\% CI $)$ & \\
\hline Household head & Men & & 51.2 & $1.326(188-2.317)$ & \\
& & & 34.6 & & \\
\hline & Women & & & $1.354(.989-3.380)$ & \\
\hline $\begin{array}{l}\text { Knowledge to } \\
\text { start } \\
\begin{array}{l}\text { complementary } \\
\text { feeding }\end{array}\end{array}$ & No & 30 & 46.2 & & \\
\hline
\end{tabular}

\begin{tabular}{|c|c|c|c|c|}
\hline $\begin{array}{l}\text { Education of } \\
\text { mother }\end{array}$ & $\begin{array}{l}\text { Illiteracy } \\
\text { Primary and } \\
\text { above }\end{array}$ & $\begin{array}{l}2 \\
258\end{array}$ & $\begin{array}{l}0.8 \\
99.2\end{array}$ & $\begin{array}{l}1.578(1.762- \\
2.292)\end{array}$ \\
\hline Income group & $\begin{array}{l}\text { Less than } 10,000 \\
\text { More than } 10,000\end{array}$ & & $\begin{array}{l}27.2 \\
40.6 \\
\end{array}$ & $1.27(.875-1.823)$ \\
\hline $\begin{array}{l}\text { Occupation of } \\
\text { mother }\end{array}$ & $\begin{array}{l}\text { H/wife } \\
\text { Skilled }\end{array}$ & & $\begin{array}{l}23.9 \\
28.6\end{array}$ & $.812(.656-1.632)$ \\
\hline Family size & $\begin{array}{l}\text { More than } 6 \\
4 \text { and below } \\
\end{array}$ & & & $\begin{array}{l}13.897(8.34- \\
21.167)\end{array}$ \\
\hline
\end{tabular}

\section{Analysis of association}

This analysis was done to find out the association between predicting factors under study and the inappropriate breastfeeding. The findings of analysis showed that the factors like number of family members, and knowledge about breastfeeding were statistically significantly related to inappropriate feeding practices whereas income source and mothers education were statistically significant to the feeding practices.

Literacy of the mother was found to have association with infant breastfeeding practices. Mothers who were illiterate were found to be two times more likely to have inappropriate feeding practices (OR1.578, CI 1.762-2.292). Similarly the household income had had no relationship with the feeding practices.

\section{Discussions}

\section{1:Age}

The minimum age of the respondents in the current study was 20 while the maximum age was 49 . The mean age was 36 years. This is in agreement with a study in Ghana which found that $63 \%$ percent of the farmers were in the age bracket of 21-40 years (Ackerson and Awuah, 2010). In Namibia as well, majority of the respondents (66.3\%) were young people falling in the age range of 21-40 (Dima, S.J et al., 2002).

In Eldoret, the mean age of respondents was 28 years (Kadenyeka, M.V. et al., 2013). In Gweru city, Zimbabwe, the average age was 41 years (Jongwe, A. 2014). In their research, Salau and Attah (2012) discovered that the mean age of the respondents was 50 years. Most $(35.56 \%)$ of the respondents were within the age of 41-50 years followed by those within the range of 51-60 years $(24.44 \%)$. In their study, Yusuf et al., (2015) found that the majority of respondents (76.1\%) were aged 41-60 years. This contradicts the findings of the current study and this is because the respondents on this study although they practiced farming they were lactating mothers. In Accra Ghana, 83\% of the farming household is of 40 years and above while $17 \%$ were between 20-29yrs of age. None of the farmers was below 30 years (Danso et al., 2004). However, Stevenson et al., (1994), states that, farming is not restricted to certain age groups.

\section{1: Marital status}

Majority of the respondents were either married (62.7\%), single (25.4\%) or divorced $(6.2 \%)$.

A study in Nigeria had findings similar to the current study. Majority (90\%) of the respondents were married while $7.78 \%$ were single (Salau and Attah, 2012). A study in Namibia found that 58\% of the 
respondents were single, $23.4 \%$ married, $13.5 \%$ cohabiting and $4 \%$ divorced and $6 \%$ separated (Dima, S.J et al., 2002). In Samre Woreda, Ethiopia, 92.3\% of the respondents were married, 5.8\% divorced and $2 \%$ widowed (Haileslassie et al., 2013). In Ibadan, Oyo state, Nigeria 90.9\% of the farmers interviewed were married (Yusuf et al., 2015).

\section{2: Education level}

43.1\% had achieved primary school education and 35.3 persons had attained Secondary ' $O$ ' level education. This was higher than the national averages in the primary education and lower in the secondary education. According to the KDHS 2014, 25\% women and 23\% men had completed primary education while $43 \%$ women and $49 \%$ men had attained post secondary education. In Nigeria, Salau and Attah (2012), also found that most $(33.33 \%)$ of the respondents had primary education while $22.22 \%$ had secondary education. About $67 \%$ of the respondents in Kumasi Ghana had dropped out or completed basic education(Ackerson and Awuah, 2010).

In a study in Eldoret, the respondents level of education was $25 \%$ for Primary and Secondary $15 \%$ (Kadenyeka, M.V. et al., 2013). In a study in Nigeria, majority of the respondents $(50.5 \%)$ had tertiary education followed by primary (25.4\%) then secondary (24\%) (Yusuf et al., 2015). In Accra Ghana a greater number of farmers interviewed had primary $(33 \%)$ or secondary $(37 \%)$ education while $6 \%$ had Tertiary education (Danso et al., 2004).

\section{3: Household size}

In this study, the maximum number of people living in households was 12 while the average number of people was 6. In Samre Woreda, Ethiopia, the mean family size was 6 . The category of $\geq 5$ persons was highest at 63.5\% (Haileslassie et al., 2013). In Ghana, Ackerson and Awuah, (2010) found the highest family size to be 5-6 (28\%). According to Stevenson et al., (1994), farm families are generally bigger than the average Dar es Salaam household (5-7 compared to 4-5 members). Larger households have a higher demand for family income and are thus using their resources to produce more of their own food (Stevenson et al. 1994). ). In Ibadan, Oyo state, Nigeria, majority of the respondents (92.3\%) had a household size of 48.

In Pretoria, South Africa the average household counted 4.4 members (Averbeke, W.V 2007). In a study in Eldoret, the Mean household size was also 4 (Kadenyeka, M.V. et al., 2013). In Gweru city, Zimbabwe, the average household size was 4.62 (Jongwe, A. 2014). In a study in Namibia, majority of respondents had household sizes ranging from 3 to 8 persons. In Windhoek $76 \%$ of the respondents had family sizes of 3-8 persons, $22 \%$ had less than 3 persons per household and only $2 \%$ had members greater than 8 . In Oshakati the respective figures were $71 \%$ with $3-8$ persons, $11 \%$ with less than 3 persons and $18 \%$ with more than 8 persons living in their families (Dima, S.J et al., 2002).

\section{4: Occupation}

Majority of the respondents in this study were business people (28.6\%) and housewives (23.9\%). These findings concur with those of Foeken and Mwangi (2000) who established that farming activities in the urban areas were mostly carried out on a part time basis by people in other livelihoods. Their participartion in urban agriculture was to supplement their family food or income. This study agrees with research conducted by the Planning Commission and the Ministry of Labour and Youth Development of Daresalaam (1995) which found that, about $30 \%$ of the urban population gains an income in the informal sector and about $6.5 \%$ of the informal urban workforce works in urban agriculture. Stevenson et al. (1996) found that, for $90 \%$ of interviewed periurban farmers, agriculture was their primary economic activity. Farming was the primary occupation of most (90\%) farmers, although they all had other sources of supplementary income, such as trading, teaching, etc (Danso et al., 2004).

The results of Salau and Attah's study (2012), showed that majority (63.33\%) of the respondents were civil servants, $22.22 \%$ with trading as their major occupation while $14.45 \%$ were full time farmers. In Zimbabwe, Mudzengerere's study (2014) showed that $55 \%$ of the respondents were unemployed whilst $24 \%$ worked in the informal sector. Only $13 \%$ were formally employed. In total, $87 \%$ of the interviewed people were unemployed and they were dependent on the informal sector for employment. In Pretoria, South Africa the contribution to mean total household income of employment was $67.1 \%$, public welfare grants $16.0 \%$, service provision $7.2 \%$, trade $7.0 \%$, transfers by kin $2.5 \%$ and agriculture $0.2 \%$ (Averbeke, W.V 2007). 


\section{5: Head of household}

In Zimbabwe, female headed families constitute $31 \%$ of the urban households and these families are vulnerable to poverty (The National Gender Policy, 2002). In Namibia, in Windhoek the male headed households were $78 \%$ and female headed households $22 \%$ while in Oshakati, the respective figures were 90 (63\%) and 53 (37\%) (Dima, S.J et al., 2002). In Accra Ghana, all the households interviewed (100\%) are headed by men (Danso et al., 2004).

\section{6: Gender}

In this study, more women $(49.7 \%)$ made decisions on what to plant in the farms than men (33.7\%). More women $(56.5 \%)$ provided labor in the farms than men $(21 \%)$. In Kumasi Ghana, majority (98\%) of the farmers practicing urban agriculture were males. Females were not so much involved in the vegetable farming (Ackerson and Awuah, 2010). In Gweru city, Zimbabwe, males were $66.4 \%$ and female $33.62 \%$ (Jongwe, A. 2014).

In their study, in Oyo state Nigeria, Yusuf et al., (2015) discovered that $85.5 \%$ of the farmers were male while $15.5 \%$ were female. In Nasarawa State Nigeria, Salau and Attah (2012), found that majority (55.56\%) of the respondents were females while $44.44 \%$ were males. Hovorka et al (2009) describe that women were the greater part of urban farmers worldwide. They comprise $80 \%$ of urban farmers in Uganda and $56 \%$ in Kenya. The farming households interviewed in Accra Ghana were predominantly (73\%) men (Danso et al., 2004)

In developing countries the prevalence of exclusive breastfeeding at six months is generally varying from 9$39 \%$ (Ulak et al., 2012). The prevalence of exclusive breastfeeding for six months in this study was at $13.5 \%$ while majority (96.2\%) of lactating mothers reported having exclusively breastfed their infants for 4 months and less. This prevalence differs from the one reported by Kenya Demographic Survey which reported that $99 \%$ of children in Kenya are exclusively breastfed (KDHS, 2014). This low prevalence in this study could be because the study targeted a smaller population unlike KDHS whose target is the whole country. The prevalence of this study is far below the WHO recommended prevalence of 90\% (Jones et al, 2003, Mogre et al., 2016) demonstrating a wide gap between the desired and the achieved practice of exclusive breastfeeding in the community under review. The low prevalence could be attributed to misconceptions regarding the insufficiency of breast milk to satisfy the infants and meet their nutritional needs without additional food or water. There is also the element of misunderstanding of certain developmental signs of the child to mean he/she is showing signs of desiring food to eat and also misunderstanding health care professional advice. The results also differs from a study done in Nepal, (Singh, 2018), which found that lactating mothers did exclusive breastfeeding at $72.7 \%$. It also differs with a study done in Gondor, Ethiopia by Muluken and Erika, 2016, which found that $97.8 \%$ of lactating mothers practiced exclusive breastfeeding and $90.9 \%$ of the same population new that breast milk is advantageous for the growth of the infant and helps to prevent childhood infections such as diarrhea, coughing, vomiting and respiratory infections. Another study done by Zang et al., 2009, found that 90\% of lactating mothers carried out exclusive breastfeeding and they gave such reasons as mothers were producing enough milk, suggestion of the elders in the family and vomiting of other feeds by the baby. Lactating women in this study gave reasons such as lack of food to eat after breastfeeding, going to do manual jobs and colic pains as reasons for not breastfeeding exclusively for 6 months. Education is usually disseminated by midwives, nutritionists and nurses and other health care professional on the importance of exclusive breastfeeding to the mothers during antenatal and post-natal clinic vists. As suggested by other studies (Lim et al., 2013, Mogre et al., 2016), findings of this study calls for an evaluation of the content of such health talks and the mothers' understanding of the message provided to them as a significant gaps in knowledge of exclusive breastfeeding.

$57.7 \%$ of lactating mothers had knowledge that an infant should be breastfed immediately after birth this knowledge concurs with the knowledge of lactating mothers in a study done in Negar Israel by Chertok, 2006, which found $86.7 \%$ of the mothers new that a child should be breastfed exclusively for 6 months. A study done in Port Harcourt, Nigeria, Yaquoet al., 2018, differs from this study in that $91.3 \%$ had correct 
knowledge on exclusive breast feeding for at least 6 months. This study also differs with a study done by in Bedelle, Southwestern, Ethiopia, by Tsedeke, 2014 which found that $91.8 \%$ knew the importance of exclusive breastfeeding. A study done in Mizan Aman, Ethiopia, by Niguse et al., 2014 also found that 91.8\% had heard about exclusive breastfeeding and 34.7\% new the recommended period for exclusive breastfeeding. This shows that knowledge on exclusive breastfeeding is well spread in the group of lactating mothers.88.5\% of the study population had prior knowledge on the recommended duration of exclusive breastfeeding. This is in agreement with a study done in Debre Birhan, Ethiopia, by Mitiku and Kebede, 2015 which found $83.4 \%$ of lactating mothers had knowledge on the recommended duration on exclusive breastfeeding for infants after delivery. A study done by Niguse et al.,2014 disagree with this study in that only $34.7 \%$ of the lactating mothers in that study had prior knowledge on the recommended duration of exclusive breastfeeding.

\section{7: Altitude of breastfeeding}

In this study majority (94.2\%) of lactating mothers had a positive attitude about exclusive breastfeeding. $48.1 \%$ agreed that breast milk alone is sufficient for the infant without additional feeds but $51.9 \%$ felt that an infant cannot be sustained by breast milk only without additional food. This study concurs with a study done in Mizan Aman, Ethiopia by Niguse et al.,2014 which found that $89.5 \%$ had a positive attitude about exclusive breastfeeding. It differs with a study done in Port Harcourt, Nigeria, Yaquo et al.,2018 which revealed that $69.3 \%$ were aware of exclusive breastfeeding. The differences between these three studies and this study could be because of the differences in the study population. A study done by Ram, 2012, in Kathmandu, Nepal revealed that $73.6 \%$ preferred their infant to be fed exclusively on breast milk and $87.3 \%$ agreed that exclusive breastfeeding for six months is advantageous to the infants. While $87.3 \%$ had the right attitude towards exclusive breast feeding. In this study $46.1 \%$ of the lactating mothers had the opinion that an infant should be breast fed exclusively for at least six months, and $52.7 \%$ said that a child should be fed on breast milk only for the first six months after delivery. While 51.9\% felt that breast milk only is not sufficient for the infant for the first six months. They were of the opinion that breast milk ought to be in cooperated with other feeds such as water, glucose, porridge and cow's milk for an infant well- being. This study differs with a study by Muluken and Erika, 2016, in Gondar Ethiopia, 76.2\% of lactating mothers preferred that a child be exclusively breastfed for six months, while $88.8 \%$ agreed that exclusive breastfeeding is advantageous to the mother and $65.7 \%$ disagreed that colostrum be discarded instead of feeding to the infant.

\section{8: Practice on exclusive breastfeeding}

In this study majority of lactating mothers $94.1 \%$ breast fed their last child. It should be noted that this is not exclusive breastfeeding it could have been in cooperated with preleacteal feeds. The lactating mothers who carried out exclusive breast feeding for at least six months in this study were $13.5 \%$. Mostly exclusive breastfeeding becomes a challenge in the African communities due to the traditional beliefs that breast milk alone is not sufficient for an infant and that once other feeds are given the child no longer cries (Nkirigacha et al,. 2016). These results concur with the results of a study done in Southern Jordan, by Cyad et al.,2017 that found that $20.9 \%$ of lactating mothers breastfed their infants exclusively for six months. These results differ with the results of a study carried out in Mizan Aman, Ethiopia by Niguse et al.,2015 which found that only $26.4 \%$ of infants were exclusively breastfed for six months after delivery. A study done in Port Harcourt, Nigeria found that $11.7 \%$ of lactating mothers carried out exclusive breastfeeding to their infants (yaquo et al., 2018). A study done in Nepal, (Jatinder et al., 2018) differs from this study in that they had $43.6 \%$ of the lactating mothers who practiced exclusive breastfeeding. This study equally differs with a study done in Gondon, Ethipia, by (Mulken and Erika, 2016) which had 97.8\% of lactating mothers six months postpartum practicing exclusive breastfeeding. The lactating mothers in the study who did not practice exclusive breastfeeding instead they, started giving cow's milk, water, water with glucose and porridge. This study concur with a study done in Nigeria (Yaquo, et al.,2018) which had 42.3\% of lactating mothers six months postpartum, who gave prelacteal feeds to their infants before six months. They reported having given glucose with water, plain water, infant formula and herbs. 
In this study $50 \%$ of lactating mothers initiated breast feeding immediately after delivery. This study is in agreement with a study done in Nigeria (Yaquo et al., 2018) which had 57.7\% of lactating mothers initiating breastfeeding after 1 hour of delivery.

The findings of analysis showed that, factors like number of family members, and knowledge about breastfeeding were statistically significantly related to inappropriate feeding practices whereas income source and mothers education were statistically significant to the feeding practices.

\section{CONCLUSIONS}

The study shows that lactating mothers six months postpartum living in urban area and educated at primary level and above were more likely to be knowledgeable and have positive attitude towards exclusive breastfeeding than their illiterate counterparts. Lactating mothers' income and occupation were positively associated with exclusive breastfeeding.

The study also showed that lactating mothers were knowledgeable about exclusive breastfeeding for six months postpartum and their attitude towards the same was positive. However their practice differed with their knowledge and altitude. There was a big gap between breastfeeding knowledge and practice. There was poor breastfeeding practice in the study community.

\section{Acknowledgement}

I would like to thank God almighty for his care and protection during the study period. I would also like to thank my husband Patrick Miriti for his love, care and provision during this study without which it would have been very hard for this study to be completed. Thanks to the Head of Department of Foods, Nutrition and Dietetics at Pwani University Prof. Jackin Njagi Nanua for his technical support during the study and my dear children Malcolm Miriti and Carol Miriti for their support and editing of my paper. Thanks to my respondents for their patience and cooperation during the study. Thanks to any other person not mentioned above but who contributed immensely to the success of this work. God bless you all.

\section{References}

[1] Jones et al 2011.How many child deaths can we prevent this year? Lancet, 2003, 362, pp.65-71.

[2] Millenium Development Goals Report; United Nations, 2011, http: //.www.un.org.

[3] Towards the under Review summit 2018: Recommendations to the EU; concord, 2010, http/www.bond.org.uk.

[4] Subbs SH, Chandrashekhar TS, Brinu VS, Joshi HS, Rana MS, Dixit SB. Infant feeding practices of mothers in an Urban area in Nepal, Kathmandu University Medical Journal 2007, 5(1) 42-47.

[5] WHO, Global Data Bank on infant and young child feeding. Geneva: WHO, 2009.

[6] Kudlova E and Rames J: Food consumption and feeding patterns of Czech INFANTS AND TODDLERS LIVING IN Prague. Eur J Clin Nutri: Epub 2006. 2007 Feb, 61(2): 239-47.

[7] Zhang J, Shi L, Wang J, and Wang Y: An infant and child feeding index is associated with child nutritional status in rural China. Early Hum Dev. 2009; 85(4): 247.Epub 2008 Nov 14.

[8] Parekh C, Bavedeka SB, Shasharo V. Study of infant feeding practices, Factors associated with family feeding; J Trop DEDIATR; 2004; 50:306-8.

[9] Camila M, Chaparo and Lutter CK. Increase in breastfeeding duration observed in Latin America and the Caribbean and the role of maternal and demorgraphic health care characteristics $=$. Food and nutrition Bulletin 2010, 31(2): 117-27.

[10] Kenya Demographic and Health Survey on exclusive breastfeeding, 2014.

[11] Laroia N, Sharma D. The religious and cultural bases for breastfeeding practices among the Hindus. Breastfeeding Medicine 2006;1(2): 94-8.

[12] Mitiku M, Damte M, Kebede Z. Factors associated with exclusive breastfeeding practices in Debre Berhan District, Central Ethiopia: a cross sectional community based study. Int Breastfeed J 2015;10:23. doi: 10.1186/s13006-015-0049-2.

[13] Bhattathiry MM, Kumari S 2010. A Study on the Infant and Young Child Feeding Practices among Mothers in a Selected Rural Area of Kollam, Kerala. Profession 2016 dec;3-6.

[14] World Health Organization. Nutrition: Exclusive Breastfeeding. http://www.who.int/ nutrition/topics/exclusive_breastfeeding/en/i ndex.html. 2010. 
[15] Yaguo Ide Lucy Eberechukwu, Uchenwa-Onyenegecha Tochi Ada 2018:, Knowledge and Practice of Exclusive Breastfeeding Among Mothers Seen at the University of PortHarcourt Teaching Hospital, American Journal of Health Research. Vol. 6, No. 1, 2018, pp. 32-36. doi: 10.11648/j.ajhr.20180601.15.

[16] Anoshirike CO, Ejeogo CP, Nwosu OIC, Maduforo AN, Nnoka Kingsley O 2014. Infant feeding practices among mothers and their infants attending maternal and child health in Enugu, Nigeria. $\mathrm{J}$ Biol Agric Healthc 2014; 4:130-139.

[17] Muluken Asfaw Admasu, Erika Cione ,2016. Breastfeeding Knowledge, Attitude, and Practice and Related Determinants Among Maternal in Gondar, Ethiopia: Cross-Sectional Study. International Journal of Nutrition and Food Sciences. Vol. 5, No. 1, 2016, pp. 25-30. doi: 10.11648/j.ijnfs.20160501.14

[18] Cyad al tamimi, m Al Nsour, Duaa Al dalaen, Neyaf Almajali,2017: Knowledge, Attitude, and Practice of Breastfeeding Among Working Mothers in South Jordan. Volume: 65 issue: 5, page(s): 210-218. https://doi.org/10.1177/2165079916665395

[19] Chertok J.R. 2006; Breast feeding initiation among post caessarean women of the Neger Israel. British Journal of Nursing. February 2008 21.p22.g205.

[20] Hoddincott P. et al (2006) 'Effectiveness of breast feeding peer coaching intervention is rural Scotland Birth 2006 March: 33(27- 22.36).

[21] Onah S, Osuorah DIC, Ebenebe J, Ezechukwu C, Ekwochi U, Ndukwu I. Infant feeding practices and maternal socio-demographic factors that influence practice of exclusive breastfeeding among mothers in Nnewi South-East Nigeria: a cross-sectional and analytical study. International Breastfeeding Journal. 2014;9:6.View ArticlePubMedPubMed CentralGoogle Scholar

[22] Edmond KM, Zandoh C, Quigley MA, Amenga-Etego S, Owusu-Agyei S, Kirkwood BR. Delayed breastfeeding initiation increases risk of neonatal mortality. Pediatrics. 2006;117:e380-6.View ArticlePubMedGoogle Scholar

[23] Mullany LC, Katz J, Li YM, Khatry SK, LeClerq SC, Darmstadt GL, Tielsch JM. Breastfeeding patterns, time to initiation, and mortality risk among newborns in southern Nepal. The Journal of Nutrition. 2008;138:599-603.PubMedPubMed CentralGoogle Scholar

[24] Singh K, Srivastava P. The effect of colostrum on infant mortality: urban rural differentials. Health and Population: Perspectives and Issues. 1992;15:94-100.Google Scholar

[25] Jones G, Steketee RW, Black RE, Bhutta ZA, Morris SS, Group BCSS. How many child deaths can we prevent this year? The Lancet. 2003;362:65-71. View ArticleGoogle Scholar

[26] Lim SS, Vos T, Flaxman AD, Danaei G, Shibuya K, Adair-Rohani H, AlMazroa MA, Amann M, Anderson HR, Andrews KG. A comparative risk assessment of burden of disease and injury attributable to 67 risk factors and risk factor clusters in 21 regions, 1990-2010: a systematic analysis for the global burden of disease study 2010. The Lancet. 2013;380:2224-60.

[27] WHO \& UNICEF. Global strategy for infant and young child feeding. Geneva: World Health Organization; New York: United Nations Children's Fund; 2003.Google Scholar

[28] Macías Y, Glasauer P, Macias Y. Guidelines for assessing nutrition-related knowledge, attitudes and practices. Rome: Food and Agricultural Organisation of the United Nations; 2014. 